\title{
RESEARCH
}

\section{SEXUAL ATTITUDE SCALE FOR ELDERLY PEOPLE: A RELIABILITY AND VALIDITY STUDY IN TURKEY}

Turkish Journal of Geriatrics

DOI: $10.31086 /$ tigeri.2021.241

2021; 24(3): 433-440

- Melisa EBEOĞLU1

-Rukiye KIZILTEPE2

- Nilgül Banu ÇENGELCi ÖZEKES²

CORRESPONDANCE

${ }^{1}$ Melisa EBEOĞLU

Ufuk University, Psychology, ANKARA, Turkey

Phone: +903125867417

e-mail: melisaebeoglu@gmail.com

Received: Mar 08, 2021

Accepted: Aug 29, 2021

${ }^{1}$ Ufuk University, Psychology, ANKARA, Turkey

${ }^{2}$ Ege University, Psychology, izmiR, Turkey

\section{Abstract}

Introduction: The purposes of this study were to translate the Sexual Attitude Scale for Elderly People into Turkish and determine its psychometric characteristics.

Materials and Method: A total of 127 people aged between 60 and 86 years participated in this study. Participants completed Turkish versions of the Sexual Attitude Scale for Elderly People, Aging Sexuality Knowledge and Attitudes Scale, and Socio-demographic Information Form. Exploratory and confirmatory factor analyses were then conducted to investigate the construct validity. In addition, the relationship between the total score of the Sexual Attitude Scale for Elderly People and attitude sub-dimension of the Aging Sexuality Knowledge and Attitudes Scale was examined for concurrent validity. Finally, discriminant validity was assessed by investigating the effect of gender and active sex-life on the total score.

Results: Similar to the original structure, both the exploratory and confirmatory factor analyses revealed a 4-factor solution: volunteerism, significance, closeness, and communication. There was a significant relationship between the total score of the Sexual Attitude Scale for Elderly People and attitude sub-dimension of the Aging Sexuality Knowledge and Attitudes Scale. Further, a series of independent sample t-tests indicated significant differences in terms of gender and active sex-life. The Cronbach alpha coefficients were .95 for the total score and between .86 and .90 for the sub-dimensions.

Conclusion: The findings of this study indicated that the scale can be used as a reliable and valid measure in Turkey.

Key words: Aged; Sexuality; Factor Analysis, Statistical; Attitude. 


\section{INTRODUCTION}

Similar to other developmental stages, aging is a period characterized by physiological, behavioral, psychological, and social changes (1). Further, it is known that changes occurring during this period affect sexuality related to the psychological well-being of the elderly. Because sexuality is an essential dimension of human life and a right for every person, it is important to understand that sexuality does not end in old age and continues to be important for elderly people (2). However, it is generally assumed (due to various sexual myths) that the majority of elderly people have lost their sexual desire or cannot perform physically (3). Today, it remains common for the elderly to be defined as lacking in sexual attraction and desire and for their sexuality to be seen as taboo $(4,5)$. In a study conducted in Turkey, these sexual myths were investigated, with one of the most widely held being "it is not appropriate for the elderly to have sexual intercourse." (3). Other myths include female sexuality ending after the menopause and sexuality only being for young people (6).

Especially in cultures where sexual myths are common, it is known that knowledge and attitudes towards sexuality (which are directly related to an active sex-life) are also affected (7). When the attitudes of elderly people towards their sexuality were examined, they were found to be generally positive. Further, elderly who had more positive attitudes tended to continue their sexual life actively (8). In their study on elderly people, Walker and Ephross found that the majority were tolerant of sexuality. Similarly, $80 \%$ of the participants stated that masturbation is an acceptable sexual activity for elderly women. It is also noteworthy that there is a consistent gender difference in the attitudes of the elderly towards their sexuality (9). For example, in a study conducted by Træen, Carvalheira, Hald, Lange, and Kvalem in Norway, Denmark, Belgium, and Portugal, elderly women were found to be more conservative compared to elderly men (10). Similarly, Waite,
Laumann, Das, and Schumm found that elderly men have a more positive attitude towards their sexuality (11). Although there are some studies on attitudes towards the sexuality of the elderly, there is a lack of literature on this subject in Turkey. Moreover, in the few studies conducted on the sexuality of the elderly, the attitudes of health personnel, students studying in health-related departments, and family members of the elderly were frequently studied rather than the attitudes of elderly people themselves (12). Considering the perspectives of the elderly and trying to understand their views and needs about their sexuality will provide an opportunity to shape the services to be provided to the elderly and increase many positive developmental outcomes (13).

The Aging Sexuality Knowledge and Attitudes Scale (ASKAS) is frequently used in the literature to measure the attitudes of elderly people towards sexuality (14). However, it would be necessary to adapt this scale for a Turkish audience, since the scale is only translated and is used without investigating its validity and reliability. Because ASKAS includes a large number of scale items, the Sexual Attitude Scale for Elderly People has emerged as an expedient and practical scale for both elderly people and researchers. Instead of evaluating attitudes as a single dimension, it is thought that evaluating the volunteering, meaningfulness, closeness, and communication dimensions will provide more information. Therefore, the aim of this study is to adapt the Sexual Attitude Scale for Elderly People scale developed by Park, Shin, and Cha for a Turkish audience and examine its psychometric properties (15).

\section{MATERIALS AND METHODS}

\section{Sample}

The study sample consisted of 127 elderly people (aged $\geq 60$ years) living in Izmir and Ankara. Participants who provide valid informed consent and understand the purpose of the study were included in the study. The participants were recruited from 
the community; therefore, hospitalized older adults and nursing home residents were not included in the study.

\section{Measures}

Socio-demographic Information Form: This form was prepared by researchers to obtain the following socio-demographic information: marital status, educational status, perceived socioeconomic level, chronic diseases, and sex-life.

ASKAS: This is used to evaluate the knowledge and attitudes of individuals towards sexuality of the elderly and was translated into Turkish by Doğan, Demir, Eker, and Karim (16). The scale has two sub-dimensions (knowledge and attitude) and 61 items in total. The first 35 knowledge questions gather basic information and are coded as "yes", "no", and "don't know", whereas the attitude questions are evaluated using a 7-point Likert type. Low scores in the knowledge dimension indicate that individuals have a high level of knowledge about the sexuality of elderly people, while low scores in the attitude dimension suggest that individuals have a more permissive attitude in terms of attitudes towards the sexuality of the elderly. It is known that this scale is commonly used to evaluate knowledge and attitudes in our country $(16,17)$. In this study, the Cronbach's alpha internal consistency coefficients for the knowledge and attitude sub-dimensions were .91 and .92, respectively.

Sexual Attitude Scale for Elderly People: This scale was developed by Park, Shin, and Cha (15) to measure the attitudes of the elderly towards sexuality, which was then adapted into Turkish within the scope of this study. The scale consists of 18 items and is evaluated using a 5-point Likert scale ( $1=$ Strongly disagree to $5=$ Strongly agree). This scale has four sub-dimensions: volunteerism (6 items), significance (4 items), closeness (5 items), and communication ( 3 items). In the original study, the Cronbach alpha coefficient was calculated as .93.

\section{Procedure}

Participants were recruited using an appropriate sampling method and snowball sampling, which are both non-random sampling methods. Data were collected between January 2019 and June 2019. After the purpose of the study was explained to the participants, their written informed consent was obtained. The scales were delivered to the participants in an envelope to reduce bias and took between 20 and 25 minutes to complete.

\section{Translation of The Sexual Attitude Scale for Elderly People into Turkish}

After obtaining the necessary permissions from the authors who developed the scale for the adaptation study, the items of the scale were translated into Turkish by three research assistants who have command of English and Turkish. These translations were reviewed by another faculty member and translated back into English. Finally, to examine the comprehensibility of the scale, the scale was applied to some elderly people, the incomprehensible items were reorganized, and the scale was finalized.

\section{Data Analysis}

The first task was to examine whether missing data were randomly distributed. According to Little's MCAR test, it was found that the missing data (chi-square $=6160.362, \mathrm{df}=6887, \mathrm{p}>$.05) were randomly distributed. Therefore, an average score was assigned to the missing data. The construct validity of the scale was then examined by exploratory and confirmatory factor analyses. Subsequently, a correlation analysis was performed to determine concurrent validity and the relationship of the scale with ASKAS scores was examined. To evaluate the discriminant validity, t-test analyses were performed and gender and active sex-life differences were examined. Finally, Cronbach alpha coefficients were used to evaluate the internal consistency of the adapted scale. All analyses were performed using SPSS 22.00 and LISREL 8.80 programs. 


\section{Ethical Issues}

Permission for the study was obtained from the Ufuk University Social and Human Sciences Scientific Research and Publication Ethics Committee (reference number: 2018-50).

\section{RESULTS}

\section{Characteristics of the Sample}

The age range of participants was $60-86$ years $(\bar{x}=$ $68.42, \mathrm{SD}=5.7)$, of which $61.4 \%(n=78)$ were female and $38.6 \%$ were male. Further, $74 \%(n=94)$ of the sample were married. Other demographic information about the sample is provided in Table 1.

\section{Construct Validity}

The construct validity of the Sexual Attitude Scale for Elderly Individuals was first evaluated by exploratory factor analysis. The Kaiser-Meyer-Olkin (KMO) coefficient and Bartlett Sphericity tests were then conducted to examine whether the data were suitable for conducting an exploratory factor analysis. The KMO coefficient of the scale was .93 and the Barlett Sphericity test was found to be significant at $p<.001$. Because the KMO coefficient was $>.50$ and the Barlett test was significant, this indicated the data set was suitable for conducting an exploratory factor analysis (18). Similar to the original structure of the scale, the number of factors was limited to four and equamax rotation was performed. The 4-factor structure explained $67.10 \%$ of the total variance. Within the scope of this study (as in the original scale), the first factor was voluntariness and the factor loads of the items ranged from .79 to .24. The factor loads of the items in the second factor (significance) varied between .74 and .30, while those in the third factor (intimacy) varied between .63 and .44. The factor loadings of the items in the final factor (communication) varied between .88 and .57.

The construct validity of the adapted scale was examined by second-order confirmatory factor analysis (CFA). In the first stage, first-order CFA was applied to the model, which consisted of 4 latent and 18 observed variables, as in the original. As a result of the first-order CFA, it was observed that the $t$ values obtained for the factor loads of all items and the relationship between latent variables were statistically significant. In addition, the first-order CFA results indicated an acceptable model fit $\left(\chi^{2}=\right.$ 189.57, $\mathrm{p}=.00, \chi^{2} / \mathrm{df}=1.50, \mathrm{RMSEA}=.063, \mathrm{NFI}=$ $.96, \mathrm{NNFI}=.98, \mathrm{CFI}=.99, \mathrm{IFI}=.99$, and $\mathrm{SRMR}=$

Table 1. Sociodemographic characteristics of the sample $(N=127)$

\begin{tabular}{|c|c|c|}
\hline Variable & Frequency & $\%$ \\
\hline \multicolumn{3}{|l|}{ Education level } \\
\hline Literate / Primary School & 55 & 43.2 \\
\hline Secondary / High School & 45 & 35.5 \\
\hline College and above & 27 & 21.3 \\
\hline \multicolumn{3}{|l|}{ Perceived SES } \\
\hline Low & 28 & 22 \\
\hline Middle & 73 & 57.5 \\
\hline High & 26 & 20.5 \\
\hline \multicolumn{3}{|l|}{ Chronic disease } \\
\hline Yes & 66 & 52 \\
\hline No & 61 & 48 \\
\hline \multicolumn{3}{|l|}{ Active sex-life } \\
\hline Yes & 73 & 57.5 \\
\hline No & 54 & 42.5 \\
\hline \multicolumn{3}{|l|}{ Frequency of sexual intercourse } \\
\hline 2-3 times a week & 5 & 3.9 \\
\hline 1 time per week & 18 & 14.2 \\
\hline Once in 2 weeks & 21 & 16.5 \\
\hline 1 per month & 8 & 6.3 \\
\hline Several times a year & 8 & 6.3 \\
\hline No & 54 & 42.5 \\
\hline
\end{tabular}


.075). In the second-order CFA, the voluntariness, significance, intimacy, and communication dimensions of the scale were tested as components of the latent variable. As a result of the second-order CFA, it was observed that the $t$ values were statistically significant for all variables. The second-order CFA results also indicated an acceptable model fit $\left(\chi^{2}=\right.$ 227.68, $\mathrm{p}=.00, \chi^{2} / \mathrm{df}=1.78, \mathrm{RMSEA}=.079, \mathrm{NFI}=$
$.96, \mathrm{NNFI}=.98, \mathrm{CFI}=.98$, and $\mathrm{IFI}=.98$ ). The ratio of $\chi^{2} / \mathrm{df}$ was found to be lower than the value of 5 recommended in the literature. Furthermore, the $\mathrm{CFI}, \mathrm{NFI}, \mathrm{NNFI}$, and IFI values were higher than the .95 suggested in the literature (19). Finally, SRMR < .08 and RMSEA were both indicators that the model data fit was acceptable (20). The values obtained as a result of second-order DFA are given in Figure 1.

Figure 1. Results of CFA of the Sexual Attitude Scale for Elderly People

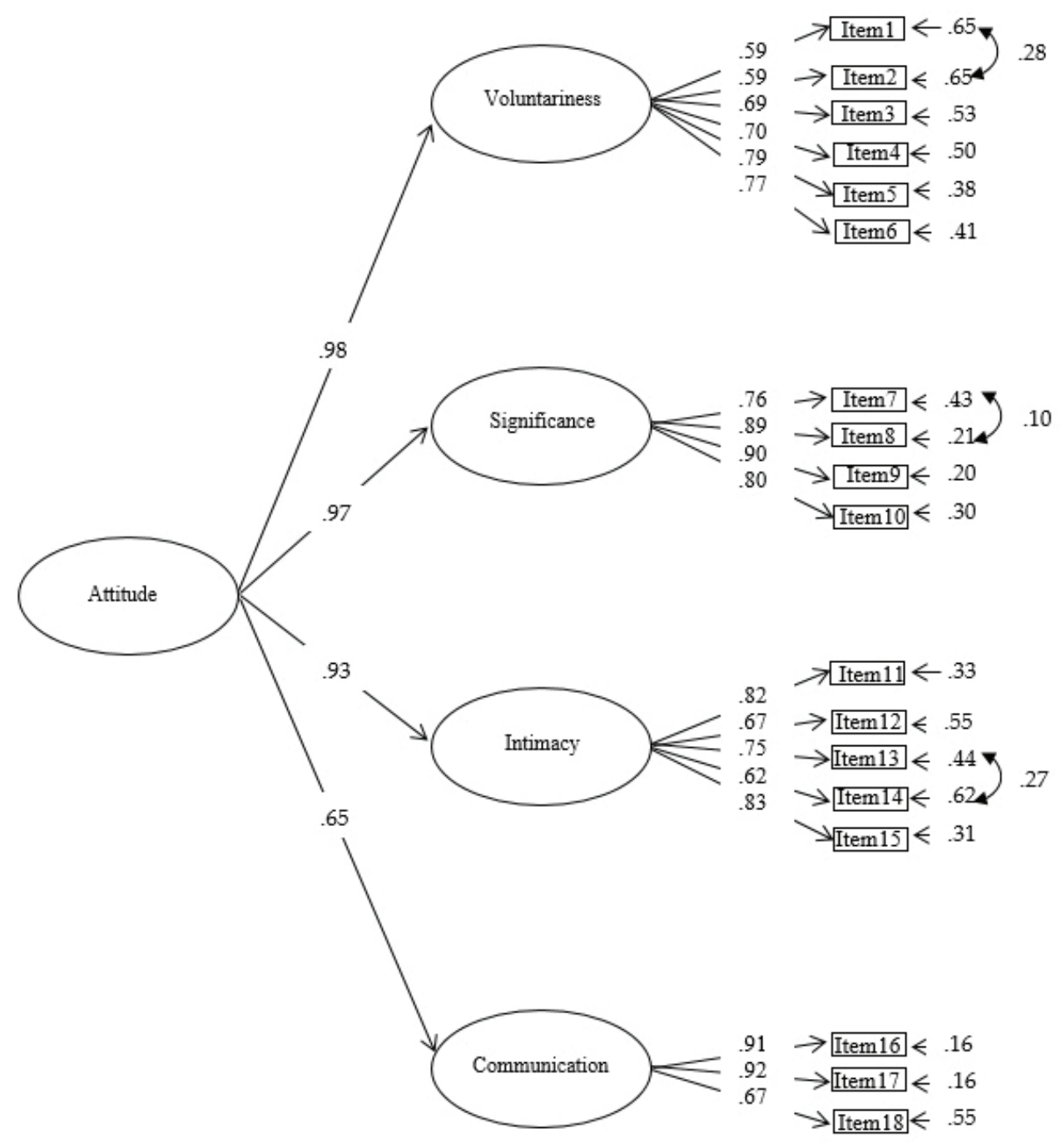




\section{Concurrent Validity}

To investigate the concurrent validity of the scale, the relationship between the attitude dimension of ASKAS (which measures a similar structure) and Sexual Attitude Scale for Elderly People was investigated. It was found that the concurrent validity was at an acceptable level and significant $(r=-.57$, $\mathrm{p}<.01)$.

\section{Discriminant Validity}

For evidence of the discriminant validity of the adapted scale, it was examined whether attitudes towards sexuality of the elderly differed according to gender. A significant difference was found according to gender in terms of attitude $(t=-3.94, p<$ .001). The scores for attitude of men $(\bar{x}=68.71 ; S D=$ 12.93) were higher than for women $(\bar{x}=58.31$; $S D=$ 15.40). Accordingly, it can be stated that elderly men are more permissive in terms of attitudes towards sexuality. In addition, it was found that attitudes towards sexuality also differed according to whether participants had an active sex-life $(t=2.84, p<.01)$. Further, attitude scores for those who continue to have an active sex-life $(\bar{x}=65.55 ; S D=14.92)$ were higher than for those who did not continue to have an active sex-life $(\bar{x}=57.96$; SD $=14.87)$. In other words, it can be said that elderly people who continue with an active sex-life are more permissive compared to those who do not continue with an active sex-life in terms of attitudes towards sexuality.

\section{Reliability}

To determine the reliability of the adapted scale, the Cronbach alpha internal consistency coefficient was calculated. Accordingly, the Cronbach alpha internal consistency coefficient for the whole scale was found to be .95 . In addition, the values were calculated as .86 for voluntariness, .90 for significance, .87 for intimacy, and .87 for communication.

\section{DISCUSSION}

The aims of this study were to translate the Sexual Attitude Scale for Elderly People developed by Park, Shin, and Cha (15) into Turkish and determine its psychometric properties. First, exploratory and confirmatory factor analyses were conducted to examine the construct validity of the scale. From these analyses, it was found that the scale preserved the 4-factor structure in our country in a similar way to the original study. In addition, it is thought that the relationship validity is acceptable since there is a statistically significant relationship between scale scores and the attitude sub-dimension of ASKAS. It is also assumed that the scale has concurrent validity when the relationship between scales that evaluate similar structures is high (21). Because there were significant differences of attitudes towards sexuality in terms of gender $(16,22)$ and active sex-life $(23)$, discriminant validity was evaluated by demonstrating the effect of gender and active sex-life on attitudes towards sexuality based on these findings in the literature. The results indicate that attitude scores obtained from the scale differ significantly according to gender and active sex-life. Thus, the scale is thought to have discriminant validity. To determine the reliability of the adapted scale, the Cronbach alpha internal consistency coefficient was calculated. Accordingly, it is possible to say that the Sexual Attitude Scale for Elderly People is a reliable measurement tool for an elderly sample, since the Cronbach alpha internal consistency coefficients for both the scale and its sub-dimensions were $>.70$ (21).

In conclusion, the scale adapted within the scope of this study has sufficient psychometric properties for an elderly sample. Furthermore, adaptation of this scale is thought to be important in terms of contributing to studies on the sexuality of the elderly in our country. Although this study makes important contributions to the literature, there are some limitations. First, the number of participants was low 
and they were only recruited from Ankara and Izmir. Hence, the generalizability of the findings is limited due to these sampling characteristics. It is suggested that working with a higher sample size and participants from different cities in future studies would contribute more to the literature. The second limitation of this study was collecting information from elderly people through self-report questionnaires. Considering this topic is taboo in our country, it should be remembered that participants might have provided biased (socially acceptable) answers. Finally, there is a need for studies that re-evaluate

\section{REFERENCES}

1. Kalra G, Subramanyam A, Pinto C. Sexuality: desire, activity and intimacy in the elderly. Indian J Psychiatry 2011;53(4):300-6. (PMID: 22303037)

2. Hajjar RR, Kamel HK. Sexuality in the nursing home, part 1: attitudes and barriers to sexual expression. J Am Med Dir Assoc 2003;4(3):152-6. (PMID: 12854989)

3. Özmen HE. Sexual myths and sexual dysfunctions. World Psychiatr 1999;3(Suppl 2):49-53. (in Turkish)

4. Bitzer J, Platano G, Tschudin S, Alder J. Sexual counseling in elderly couples. J Sex Med 2008;5(9):202743. (PMID: 18637999)

5. Weeks D. Sex for the mature adult: health, self-esteem, and countering ageist stereotypes. Sex Relation Ther 2002;17(3):231-40. (DOI: 10.1080/14681990220149031)

6. Astbury-Ward EM. Menopause, sexuality and culture: is there a universal experience? Sex Relation Ther 2003;18(4):437-45. (DOI: 10.1080/14681990310001609787)

7. VB Agocha, M Asencio, CU Decena. Sexuality and culture, In:Deborah L. Tolman, Lisa M. Diamond, José A. Bauermeister, William H. George, James G. Pfaus, L. Monique Ward (Eds). APA handbooks in psychology®. APA handbook of sexuality and psychology, Vol. 2. Contextual approaches, American Psychological Association, USA 2014, pp 183-228.

8. DeLamater J, Moorman SM. Sexual behavior in later life. J Aging Health 2007;19(6):921-45. (PMID: 18165289) the relationships between variables related to attitudes towards elderly sexuality using the adapted scale.

Acknowledgement: The research was supported by the Ege University Scientific Research Projects Coordination (No: 17-EDB-011). The authors thank the Ege University Scientific Research Projects Coordination for supporting this study. The authors also grateful to the volunteer participants.

Conflict of Interest: We have no conflicts of interests to disclose.

9. Walker BL, Ephross PH. Knowledge and attitudes toward sexuality of a group of elderly. J Gerontol Soc Work 1999;31(1-2):85-107. (DOI: 10.1300/ J083v31n01_06)

10. Træen B, Carvalheira AA, Hald GM, Lange T, Kvalem IL. Attitudes towards sexuality in older men and women across Europe: similarities, differences, and associations with their sex lives. Sex Cult 2019;23(1):1-25. (DOI: 10.1007/s12119-018-9564-9)

11. Waite LJ, Laumann EO, Das A, Schumm LP. Sexuality: Measures of partnerships, practices, attitudes, and problems in the National Social Life, Health, and Aging Study. J Gerontol B Psychol Sci Soc Sci 2009;64(1):56-66. (PMID: 19497930)

12. Gewirtz-Meydan A, Hafford-Letchfield T, Ayalon L et al. How do older people discuss their own sexuality? A systematic review of qualitative research studies. Cult Health Sex 2019;21(3):293-308. (PMID: 29863969)

13. Gott $M$, Hinchliff $S$. How important is sex in later life? The views of older people. Soc Sci Med 2003;56(8):1617-28. (PMID: 12639579)

14. White CB. A scale for the assessment of attitudes and knowledge regarding sexuality in the aged. Arch Sex Behav 1982;11(6):491-502. (PMID: 7159218)

15. Park H, Shin S, Cha H. Development and validation of a Sexual Attitude Scale for Elderly Korean People. J Korean Gerontol Nurs 2014;16(3):189-200. (DOI: 10.17079/jkgn.2014.16.3.189)

16. Doğan S, Demir B, Eker E, Karim S. Knowledge and attitudes of doctors toward the sexuality of older 
people in Turkey. Int Psychogeriatr 2008;20(5):101927. (PMID: 18405397)

17. Şen S, Usta E, Aygın D, Sert H. Approaches of health professionals on aging and sexuality. Andrology Bulletin 2015;17(60):64-7 (in Turkish)

18. BG Tabachnich, LS Fidell. Using multivariate statistics, $6^{\text {th }}$ edition, Pearson, Boston 2013, pp 619-20.

19. RE Schumacker, RG Lomax. A beginner's guide to structural equation modeling. 2nd edition, Lawrence Erlbaum, Hillsdale, New Jersey 2004, pp 85-88.

20. Hu LT, Bentler PM. Cutoff criteria for fit indexes in covariance structure analysis: conventional crite- ria versus new alternatives. Struct Equ Modeling 1999;6(1):1-55. (DOI: 10.1080/10705519909540118)

21. RM Furr. Psychometrics: an introduction, 3th edition, Sage, California 2017.

22. Fisher L. Sex, romance, and relationships: AARP survey of midlife and older adults [e-book] AARP; 2010. [Internet]. Available from: http://assets.aarp.org/rgcenter/general/srr_09.pdf Accessed: 10.01.2021.

23. Wang TF, Lu CH, Chen IJ, Yu S. Sexual knowledge, attitudes and activity of older people in Taipei, Taiwan. J Clin Nurs 2008;17(4):443-50. (PMID: 18205677) 